\title{
Brote de gripe A HINI en la base española de Camp "Arema» (Herat, Afganistán) durante julio y agosto de 2009. Parte I: Características clínicas y reducción de la duración de la fiebre con el uso de oseltamivir
}

\author{
Maimir Jané F¹, García Ortiz JM², Sánchez Gil MA³, García de Guadiana RL4, Gutiérrez Ortega C5
}

Sanid. mil. 2011; 67 (1): 6-10; ISSN: 1887-8571

\begin{abstract}
RESUMEN
Introducción: Desde la declaración de alerta fase 6 por la OMS se han presentado brotes de gripe A H1N1 en todo el mundo. Presentamos los resultados del estudio realizado en el brote de nueva gripe A H1N1 en la Base Militar de Camp Arena en Herat (Afganistán). Método: Estudio prospectivo de serie de casos, de pacientes controlados por el Servicio de Sanidad del Role 2, valorando la edad, síntomas al ingreso, duración de la fiebre, test de despistaje rápido, complicaciones, intolerancia al oseltamivir. En el grupo inicial de paciente se valoró RT-PCR. Se compararon los grupos con y sin tratamiento con oseltamivir para la duración de la fiebre. Resultados: Estudio de 106 pacientes, con edad media 27,17 años, los síntomas más frecuentes fueron la tos seca y mal estado general. Los pacientes tratados sin oseltamivir presentaron una duración media de la fiebre de 3,71 días, y con oseltamivir de 2,54 días ( $\mathrm{p}<0,001)$. Se presentaron un total de 13 complicaciones, la más frecuente la bronquitis. Se presentó intolerancia al oseltamivir en el 11,29\% de los pacientes. Conclusiones: el tratamiento con oseltamivir reduce la duración de la fiebre significativamente, con aparición de efectos secundarios que obligan a suspender el tratamiento en el 11,29\% de los pacientes.
\end{abstract}

PALABRAS CLAVE: Gripe A H1N1, Afganistán, Fuerzas Armadas, Oseltamivir.

Outbreak of new influenza a H1N1 in Spanish base Camp «Arena» (Herat, Afghanistan) during july and august 2009. Part I: Clinical features and reducing the duration of fever with the use of oseltamivir during the outbreak of new influenza A H1N1 in Spanish forces in Afghanistan.

SUMMARY

Introduction: Since the warning statement of Phase 6 by WHO, the world has presented Influenza A H1N1 outbreaks. We present the results of the study of a new Influenza A H1N1 outbreak in the Military Base Camp Arena, in Heart (Afghanistan). Methods: Prospective case series of patients monitored by the Health Service of the Role 2, assessing the age, symptoms at admission, duration of fever, rapid screening test, complications, intolerance to oseltamivir. The initial group of patients was evaluated RT-PCR. We compared groups with and without treatment with oseltamivir for the duration of fever. Results: Study of 106 patients, mean age 27.17 years, the most common symptoms were dry cough and general disrepair. Patients without oseltamivir showed an average of 3.71 days of fever and with oseltamivir of 2.54 days ( $p<0.001$ ). There were a total of 13 complications, the most frequent bronchitis. Intolerance to oseltamivir was presented in 11.29\% of patients. Conclusions: Oseltamivir reduces the duration of fever significantly, with onset of adverse reactions that require discontinuation of therapy in $11.29 \%$ of the treated cases.

KEY WORDS: New Influenza A H1N1, Afghanistan, Armed Forces, Oseltamivir.

\section{INTRODUCCIÓN}

El día 10 de julio de 2009, en la Base española Camp Arena de Herat (Afganistán) se presentaron cinco casos de fiebre, malestar general y síntomas de faringitis. Todos ellos se habían incorporado a Zona de Operaciones en el vuelo del 7 de julio de España a Manás, bautizado como vuelo «San Fermín». Tras valorarlos, ¿podría ser la tan temida gripe A?

${ }^{1}$ Cte. Médico. Hospital Central de la Defensa. Unidad de Cuidados Intensivos. Madrid. España. ${ }^{2}$ Cte. Médico. Hospital General de la Defensa San Carlos. San Fernando, Servicio de Neumología. Cádiz. España.

${ }^{3}$ Cte. Médico. Escuela Militar de Sanidad. Departamento de Medicina. Madrid. España.

${ }^{4}$ Cte. Farmacéutico. Clínica Militar. Servicio de Análisis Clínicos. Cartagena. España.

${ }^{5}$ Hospital Central de la Defensa. Servicio de Medicina Preventiva, Madrid. España.

Dirección para correspondencia: Dr. Félix Maimir Jané. Unidad de Cuidados Intensivos, Hospital Central de la Defensa. Glorieta del Ejército s/n. 28047 Madrid. 28047 Madrid. felixmaimir@wanadoo.es

Recibido: 27 de noviembre de 2009

Aceptado: 21 de septiembre de 2010
En el mes de marzo se detectó en Méjico la aparición de una enfermedad respiratoria agresiva y fácilmente contagiosa, que un mes más tarde afectaba a Estados Unidos, y que se identificó como una variante del virus de la gripe A (H1N1). El 27 de abril de 2009 la OMS declaró la fase 4 de alerta pandémica al comprobarse la transmisión interhumana y su capacidad de causar brotes comunitarios, el 29 de abril se declaró la fase 5 al presentarse de forma sostenida la fase 4 en dos países de una región mundial. El 11 de junio de 2009 la OMS declaró la fase 6 , al afectarse pacientes en dos regiones.

La difusión de la nueva gripe A H1N1 ha sido desde un principio rápida y amplia, el 2 de julio había 111 países afectados, más de 75.000 casos confirmados, y 339 fallecimientos ${ }^{1}$.

El 19 de mayo de 2009 se produjo el primer brote en las Fuerzas Armadas españolas, como se hizo eco la prensa y se publicó en el interesante artículo de Fe et al en la revista de Sanidad Militar ${ }^{2}$. Las Fuerzas Armadas desempeñan actualmente su función en cuatro continentes, y como era de esperar, la alta movilidad de nuestras tropas puede producir este tipo de brotes allí donde se encuentre un número suficiente de efectivos. Este fue el caso en Afganistán, y esta nuestra experiencia. 
Los autores realizamos el presente estudio ante la sospecha de un brote epidémico, de causa inicialmente sospechada, confirmada por laboratorio, y que puso a prueba las capacidades sanitarias de las Fuerzas Armadas españolas en un despliegue en una Zona de Operaciones de altas exigencias. Sirva nuestra experiencia como ejemplo del complicado quehacer diario de las Unidades Sanitarias del ejército español.

\section{MÉTODO}

Estudio prospectivo de serie de casos.

Población de estudio: personal que trabajaba en la Base española de Camp «Arena» (Afganistán), que incluía 1.024 personas destinadas en la Forward Support Base (FSB), y un número variable de personal multinacional contratado por la UTE (compañía de servicios).

Criterios de inclusión: paciente con diagnóstico de gripe A (H1N1) realizado mediante los criterios diagnósticos vigentes en el momento del estudio y publicados por el Ministerio de Sanidad y Consumo (versión del 7 de julio de 2009)33.

Criterios de exclusión: no seguir control por el Servicio de Sanidad españoles de la Base española de Camp «Arena» (Afganistán).

Variables estudiadas: edad, sexo, fecha ingreso, fecha inicio de los síntomas, síntomas en el momento del ingreso, fecha de fin de la fiebre sin uso de antitérmicos durante 12 horas (ausencia de fiebre, sin ser atribuible la normotermia al uso de antitérmicos), resultado del test de despistaje rápido BinaxNOW Influenza A\&B en exudado nasofaríngeo, presencia de complicaciones, tratamiento con Tami$\mathrm{flu}^{\circledR}$, efectos secundarios al tratamiento con intolerancia al Tamiflu ${ }^{\circledR}$, días de ingreso.

Se realizó estudio mediante RT-PCR de nuevo virus de la gripe $\mathrm{A}(\mathrm{H} 1 / \mathrm{N} 1)$ de exudado nasal en 25 casos, correlacionándose con el despistaje rápido BINAX Now Influenza A\&B.

Protocolo clínico aplicado a los pacientes: todos los pacientes que cumplieron los criterios de inclusión fueron ingresados en unidades de hospitalización de cuidados mínimos habilitadas en el Role 2 de la Base Camp «Arena» en el aeropuerto de Herat (Afganistán). Desde el inicio del brote los pacientes no recibieron Tamiflu ${ }^{\circledR}$ al no existir

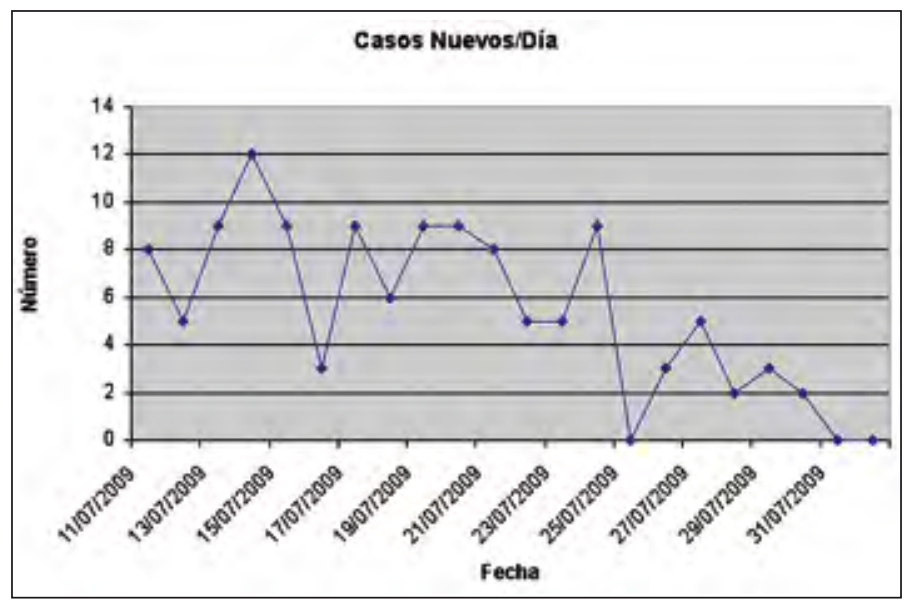

Figura 1. Número de ingresos diarios en el Role 2 durante el periodo de brote de gripe A (11 de julio al 31 de julio de 2009). Los pacientes incluidos en el estudio corresponden a los nuevos casos del 11 de julio al 24 de julio (a.i). existencias en la farmacia del Role 2 (Grupo A). Tras la llegada del fármaco, tal y como indicaban los protocolos vigentes, se administró Tamiflu $^{\circledR}$ a todos los pacientes (Grupo B). Se mantuvo a todos los pacientes 7 días ingresados desde el inicio de los síntomas o 24 horas sin fiebre si esta era superior a 7 días. Posteriormente eran controlados durante 72 horas por el Role 1 de la Unidad de origen o en su defecto por Triage del Role 2, hasta su reincorporación al servicio.

Se comprobó que las distribuciones de las poblaciones según los días de duración de la fiebre vulneraban el principio de normalidad, por lo que realizó comparación de rangos empleando el test de U de Mann-Whitney para muestras independientes, valorando el efecto mediante la diferencia de medianas.

\section{RESULTADOS}

De los 121 casos finales incluidos en el brote de gripe, se incluyeron en el estudio los 106 primeros casos. Estos casos fueron incluidos del 11 de julio al 24 de julio de 2009. La primera alta hospitalaria fue dada el 17 de julio, y el último paciente dado de alta incluido en el estudio fue el 30 de julio.

La edad media fue de 27,17 años, con valor mínimo de 19 años y máximo de 56 años. Se incluyeron en el estudio a 100 hombres y 6 mujeres.

En la figura 1 se reflejan el número de nuevos ingresos por gripe en los días en los que duró el brote. En la tabla 1 los nuevos casos, los casos acumulados y el número de pacientes ingresados en el Role 2 (capacidad de camas de hospitalización: 14).

Tabla 1. Casos acumulados, nuevos casos e ingresados durante el brote de gripe. Los pacientes incluidos en el estudio fueron los casos acumulados del 11 al 24 de julio (a.i).

\begin{tabular}{|c|c|c|c|c|}
\hline Fecha & $\begin{array}{c}\text { Casos } \\
\text { acumulados }\end{array}$ & $\begin{array}{l}\text { Nuevos } \\
\text { casos }\end{array}$ & Altas & Ingresados \\
\hline $11 / 07$ & 8 & 8 & 0 & 8 \\
\hline $12 / 07$ & 13 & 5 & 0 & 13 \\
\hline $13 / 07$ & 22 & 9 & 0 & 22 \\
\hline $14 / 07$ & 34 & 12 & 0 & 34 \\
\hline $15 / 07$ & 43 & 9 & 0 & 43 \\
\hline $16 / 07$ & 46 & 3 & 0 & 46 \\
\hline $17 / 07$ & 55 & 9 & 8 & 47 \\
\hline $18 / 07$ & 61 & 6 & 15 & 38 \\
\hline $19 / 07$ & 70 & 9 & 3 & 44 \\
\hline $20 / 07$ & 79 & 9 & 5 & 48 \\
\hline $21 / 07$ & 87 & 8 & 12 & 44 \\
\hline $22 / 07$ & 92 & 5 & 12 & 37 \\
\hline $23 / 07$ & 97 & 5 & 6 & 36 \\
\hline $24 / 07$ & 106 & 9 & 3 & 42 \\
\hline $25 / 07$ & 106 & 0 & 11 & 31 \\
\hline $26 / 07$ & 109 & 3 & 7 & 27 \\
\hline $27 / 07$ & 114 & 5 & 8 & 24 \\
\hline $28 / 07$ & 116 & 2 & 8 & 18 \\
\hline $29 / 07$ & 119 & 3 & 8 & 13 \\
\hline $30 / 07$ & 121 & 2 & 6 & 9 \\
\hline
\end{tabular}


Tabla 2. Frecuencia y porcentaje de síntomas al ingreso de los pacientes incluidos en el estudio.

\begin{tabular}{|lccc|}
\hline \multicolumn{1}{|c}{ Síntomas } & Pacientes & $\begin{array}{c}\text { Porcentaje (total } \\
\text { 106 pacientes) }\end{array}$ & $\begin{array}{c}\text { Porcentaje informado } \\
\text { en 06 Julio }\end{array}$ \\
\hline Tos & 59 & $55,6 \%$ & $91,4 \%$ \\
Tos seca & 55 & $51,8 \%$ & $62,5 \%$ \\
Tos productiva & 4 & $3,7 \%$ & $20,4 \%$ \\
Malestar general & 55 & $51,8 \%$ & $73,9 \%$ \\
Cefalea & 43 & $40,5 \%$ & $64,4 \%$ \\
Rinorrea & 9 & $8,4 \%$ & $60,7 \%$ \\
Dolor de & 54 & $50,9 \%$ & $57,3 \%$ \\
garganta & & & \\
Mialgia & 17 & $16,0 \%$ & $54,9 \%$ \\
Artralgia & 6 & $5,6 \%$ & $26,5 \%$ \\
Diarrea & 5 & $4,7 \%$ & $16,7 \%$ \\
Conjuntivitis & 0 & $0,0 \%$ & $14,1 \%$ \\
Vómitos & 2 & $1,8 \%$ & $10,0 \%$ \\
Nauseas & 1 & $0,9 \%$ & $8,4 \%$ \\
Laringitis & 1 & $0,9 \%$ & - \\
Otalgia & 1 & $0,9 \%$ & - \\
Mareo & 4 & $3,7 \%$ & - \\
\hline
\end{tabular}

Los síntomas presentes en el momento del ingreso se encuentran reflejados en la tabla 2. Los síntomas más frecuentes fueron la tos seca, el malestar general y el dolor de garganta. La cefalea fue el siguiente síntoma en frecuencia, pero estrechamente relacionado con la fiebre.

En la tabla 3 se presenta la frecuencia de duración de la fiebre, y la incidencia de aparición de complicaciones con la misma. La administración de antitérmicos se realizó a los pacientes con temperatura axilar superior a $37,5^{\circ} \mathrm{C}$, definiéndose como criterio de fin de la fiebre al paciente que presentaba por más de 12 horas temperatura igual o menor de $37,5^{\circ} \mathrm{C} \sin$ la administración de fármacos antitérmicos.

Los pacientes atendidos inicialmente no recibieron Tamiflu ${ }^{\circledR}$ por no tenerlo en existencias la farmacia del Role 2. Por lo que los pacientes iniciales hasta la recepción del fármaco constituyeron el

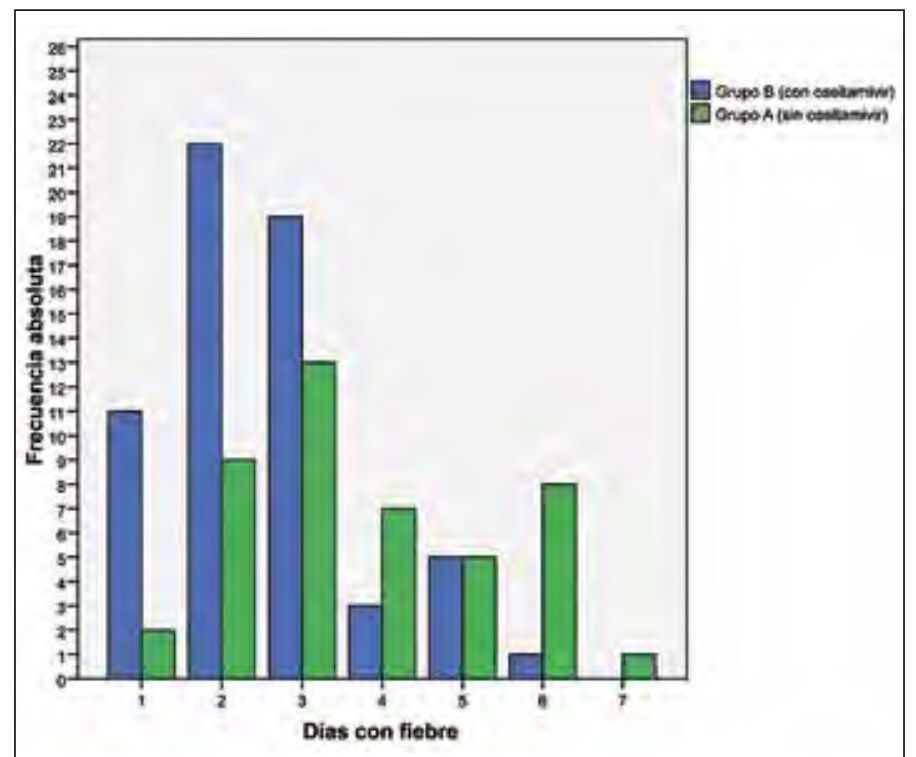

Figura 2. Frecuencias absolutas y duración de la fiebre en días en los dos grupos estudiados.

grupo A. Una vez recibido el Tamiflu ${ }^{\circledR}$, se inició su administración siguiendo los protocolos vigentes en ese momento, constituyéndose el grupo B. Se expresa en la tabla 3 la duración de la fiebre desde el inicio de los síntomas, en el grupo de pacientes que tomó Tamiflu ${ }^{\circledR}$ comparado con el grupo inicial que no lo tomó (Figura 2). Se reflejan, así mismo las complicaciones de ambos grupos. De las siete pacientes con complicaciones por toma de Tamiflu ${ }^{\circledR}$ se ha incluido en el grupo de pacientes no tratados al paciente que presentó intolerancia con vómito en la primera dosis. La media de duración de la fiebre en los pacientes tratados con Tamiflu ${ }^{\circledR}$ fue de 2,54 días, y en los pacientes que no recibieron el tratamiento fue de 3,71 días. Tras valorar que la distribución de los grupos estudiados vulnera el principio de normalidad, se han valorado los rangos de cada grupo (tabla 4). Se ha comparado ambos grupos mediante la U de MannWhitney para la duración de la fiebre existiendo diferencias significativas entre ambos grupos, $\mathrm{p}<0,001$ (tabla 5).

Tabla 3. Duración de la fiebre desde el inicio de los síntomas de gripe en los grupos de paciente que recibieron Tamiflu ${ }^{\circledR}$ los que no, con expresión de las complicaciones observadas.

\begin{tabular}{|c|c|c|c|c|c|}
\hline \multirow{2}{*}{$\begin{array}{c}\text { Duración de la fiebre } \\
\text { (en días) }\end{array}$} & \multicolumn{2}{|c|}{ Pacientes con tratamiento sin $\operatorname{Tamiflu}^{\circledR}($ Grupo A) } & \multicolumn{3}{|c|}{ Pacientes con tratamiento con Tamiflu ${ }^{\circledR}$ (Grupo B) } \\
\hline & Casos & Complicaciones & Casos & Complicaciones & Intolerancia al Tamiflu ${ }^{\mathbb{R}}$ \\
\hline 1 & 2 & 1 (neumonia) & 11 & & Gastritis \\
\hline 2 & 9 & & 22 & 1 (citolisis hepática) & $\begin{array}{c}\text { Gastritis, Diarrea } \\
\text { Ansiedad }\end{array}$ \\
\hline 3 & 13 & 2 (bronquitis) & 19 & $\begin{array}{c}3 \text { ( } 2 \text { bronquitis } 1 \\
\text { agudización asma) }\end{array}$ & $\begin{array}{c}\text { Gastritis } \\
\text { Diarrea }\end{array}$ \\
\hline 4 & 7 & & 3 & 1 (bronquitis) & \\
\hline 5 & 5 & 1 (bronquitis) & 5 & $\begin{array}{c}2 \text { ( } 1 \text { bronquitis } 1 \\
\text { faringoamigdalitis) }\end{array}$ & \\
\hline 6 & 8 & 1 (bronquitis) & 1 & & \\
\hline 7 & 1 & 1 (otitis) & 0 & & \\
\hline$>7$ & 0 & & 0 & & \\
\hline Casos totales & 45 & 6 & 61 & 7 & 6 \\
\hline Media (días) & 3,71 & & 2,54 & & \\
\hline
\end{tabular}


Tabla 4. Rangos de los grupos de pacientes estudiados (sin oseltamivir, y con oseltamivir).

\begin{tabular}{|llrcc|}
\hline \multicolumn{1}{c}{ Grupo } & N & Rango promedio & Suma de rangos \\
\hline \multirow{2}{*}{ Días } & Con oseltamivir & 61 & 43,73 & 2667,50 \\
& Sin oseltamivir & 45 & 66,74 & 3003,50 \\
\hline \multicolumn{2}{|c}{ Total } & 106 & & \\
\hline
\end{tabular}

Se presentó intolerancia al tratamiento con Tamiflu ${ }^{\circledR}$ en 7 de los 61 pacientes, en el 11,29\% (Tabla 3). En todos estos pacientes se suspendió el tratamiento.

Las complicaciones presentadas por el proceso de gripe fueron un total de $13(12,26 \%)$. Se presentaron 8 bronquitis, 1 otitis, 1 neumonía, 1 agudización de asma, 1 faringoamigdalitis bacteriana, y 1 citolisis hepática, distribuidas según los grupos como puede observarse en la tabla 3. Como se aprecia, la duración de la fiebre no se relacionó con la presencia o no de complicaciones. La presencia de un paciente con elevación de transaminasas se interpretó por fiebre alta persistente a pesar del tratamiento antitérmico inicial.

De los pacientes que fueron diagnosticados de nueva gripe, cuatro pertenecían al personal del Role 2, por lo que la incidencia de gripe A en el personal sanitario o destinado en el Role 2 fue del 13,3\%.

Se realizaron un total de 53 determinaciones de despistaje de la Gripe A/B mediante torunda de exudado nasofaríngeo, con 24 resultados positivos para Gripe $A$, ningún resultado positivo para Gripe B, y 29 pacientes negativos para Gripe A y B.

Se remitieron a España 25 muestras para detección por RT-PCR de nuevo virus de la Gripe A (H1/N1), de las que 22 fueron positivas a nuevo virus de la gripe A (H1/N1), y 3 negativas. Se puede observar en la tabla 6 la comparación de resultados en los pacientes a los que se realizó ambas pruebas. La sensibilidad del BinaxNOW Influenza A\&B fue del $50 \%$, con una especificidad del $66 \%$, un valor predictivo positivo de 0,91 y valor predictivo negativo de 0,15 .

\section{DISCUSIÓN}

No existen referencias publicadas en el momento actual de epidemias de Gripe A en poblaciones cerradas o aisladas. Las características de una base militar en misión el extranjero, en una misión «cerrada» como es la de un contingente en una zona de conflicto crea una situación única sólo comparable a la una población carcelaria en nuestro medio habitual. Los informes del Ministerio de Sanidad sobre brotes de casos agrupados, señalan tasas de ataque menores del $24 \%$ en el $71,2 \%$ de los casos, pero algunos colectivos (centro de acogida, club deportivo o campamento de verano) han presentado tasas superiores al $50 \%{ }^{4}$.

En la valoración de la edad y sexo es lógico destacar el sesgo que representa una población de militares en activo en una misión internacional, por lo que este dato no es comparable. Los datos de edad, tal vez serán comparables con los que puedan publicarse de los brotes que se han producido en los últimos meses en algunos centros penitenciarios.

Los pacientes ingresados, casos, presentaron una curva ascendente de 7 días, llegando a los 47 casos ingresados y un segundo pico a los 4 días, con 48 casos ingresados. Posteriormente, al decimocuarto día se produjo una reducción en el número de pacientes ingresados hasta la declaración de finalización del brote que se realizó el 13 de agosto.
Tabla 5. Estadísticos de contraste (a) de los grupos estudiados (tabla 4).

\begin{tabular}{|lc|}
\hline & Días \\
\hline U de Mann-Whitney & 776,500 \\
W de Wilcoxon & 2667,500 \\
Z & $-3,922$ \\
Sig. asintót. (bilateral) & $<0,001$ \\
\hline
\end{tabular}

a Variable de agrupación: grupo

Tabla 6. Correlación del test de despistaje rápido (*BinaxNOX Influenza $A \& B$ ) y el resultado de la PCR en los pacientes incluidos en el estudio a los que se realizó ambas pruebas.

\begin{tabular}{|lcc|}
\hline \multirow{2}{*}{ Test Despistaje rápido } & \multicolumn{2}{c|}{ PCR } \\
\cline { 2 - 3 } & Positivo & Negativo \\
\hline Positivo & 11 & 1 \\
Negativo & 11 & 2 \\
\hline
\end{tabular}

La tasa de ataque del brote fue del 11,32\% (116 sobre 1024), siendo en el $71,2 \%$ de los brotes declarados menor del $24 \%{ }^{4}$, con una media del $21,2 \%$. De los 121 pacientes diagnosticados, 116 fueron personal militar español y 5 personal civil contratado en la base. En nuestro caso la tasa de ataque fue la mitad de la publicada para grupos similares. Esto puede deberse a la baja comorbilidad de la población, no existir pacientes de riesgo, las medidas de aislamiento que se implantaron, o a otros factores de difícil evaluación en un medio tan hostil como una base militar en Asia (pacientes enfermos que no acudieron a consulta, personal que se ausentó en convoys de uno a varios días y no se diagnosticó, etc.).

La duración total del brote, desde el inicio hasta el último caso que se presentó fue de 19 días. Esta evolución recortada en el tiempo se debe al tratarse de una población «aislada». La media de duración en los brotes cerrados en España fue de 21 días (rango de entre 7 y 37 días) ${ }^{4}$, siendo nuestros datos similares.

Las tasas de casos/seroconversión varían del 1/14 en la primera ola de la gripe del 1918, 1/6 en la segunda ola de la gripe del 1918, o $1 / 2$ en la gripe de $1957^{5}$, por lo cual podemos valorar que la finalización del brote puede deberse a que existía una amplia parte de la población inicial que había presentado seroconversión (casos y conversión serológica sin clínica) durante este periodo. En nuestro caso no puede deberse a la dispersión de la población susceptible siendo remitida para aislamiento en domicilio, como se ha realizado en algunos brotes en el mismo periodo en España.

Los síntomas más frecuentes fueron el malestar general, la tos seca y el dolor de garganta $(51,8 \%, 51,8 \%$ y $50,9 \%$ respectivamente). Si comparamos los datos con los publicados ${ }^{6}$ la presencia de síntomas en nuestra población fue menor, aunque puede deberse a que hemos reflejado los síntomas acumulados hasta el diagnóstico clínico, en contraposición con los reflejados por el Ministerio de Sanidad en que se señalan los síntomas acumulados en el proceso. Se trataba de una población sana previamente sin comorbilidades, y joven (tabla 2). En nuestra población la tos no productiva fue poco frecuente, así como las mialgias, en comparación con los datos publicados en ese momento.

El criterio de fin de la fiebre fue el de 12 horas sin fiebre en paciente sin toma de antitérmicos. Se controlaba la temperatura cada 6 horas, con lo cual eran obligadas dos tomas consecutivas con tem- 
peratura menor de $37,5^{\circ} \mathrm{C}$ sin toma de antitérmicos. Se tomó este criterio al fin de lograr una definición objetiva y cuantificable de la variable, evitando la subjetividad de los síntomas de los pacientes. Nuestros resultados son concordantes con los de la literatura, si lo correlacionamos con la duración de los síntomas. Así en el metanálisis de Burch et $\mathrm{al}^{7}$ indica que en 4 ensayos con un total de 1410 pacientes el oseltamivir redujo la duración de los síntomas en 0,55 días ( $\mathrm{p}=0,008)$, presentando una reducción significativa de la duración de la fiebre en el grupo tratado con oseltamivir $(\mathrm{p}<0,001)$.

Las complicaciones observadas fueron secundarias principalmente a sobreinfección respiratoria (1 neumonia y 8 bronquitis). En total fueron 13 de 106 pacientes $(12,26 \%)$, muy superior al 3,7\% publicado por el Subcomité de Vigilancia del Ministerio de Sanidad y Política Social ${ }^{4}$.

Los efectos secundarios a la toma de oseltamivir se presentaron en el $11,29 \%$ de los pacientes. Todas descritas en ficha técnica. Las más frecuente fueron la gastritis ( 3 de 61 pacientes), y la diarrea (2 de 61 pacientes). En ficha técnica se presentan los efectos secundarios de nauseas en el 7,9\% y dolor abdominal en el 2,2 \%, y la diarrea en un $5,5 \%$ de los pacientes ${ }^{8}$.

Respecto al método diagnóstico se confirmaron por RT-PCR 22 casos de los 106 incluidos en el estudio. El 20,75\% se diagnosticó por RT-PCR y el resto por vínculo epidemiológico. En los brotes atendidos en España el porcentaje de diagnóstico por laboratorio fue de $23,1 \%{ }^{4}$, y el resto lo fueron por vínculo epidemiológico, datos similares a los de nuestro estudio.

De las 25 muestras a las que se les realizó RT-PCR, 22 fueron positivas, siendo de éstas sólo 11 positivas en la determinación del test rápido de despistaje (BinaxNOW Influenza A\&B). Los resultados de sensibilidad del $70 \%$ y especificidad del $90 \%$ ofrecidos por la casa comercial difieren significativamente de nuestros resultados ${ }^{9}$, con sensibilidad del $50 \%$ y especificidad del $66 \%$, valorando únicamente a los pacientes a los que se les realizó ambos estudios.

La toma de muestras se realizó en los pacientes que fueron negativos en el RT-PCR a las 24 horas (un paciente) y 48 horas (dos pacientes) del inicio de los síntomas. En los pacientes con resultado positivo a nueva gripe A H1N1 la toma de muestra se realizó desde a un paciente a los 7 días del inicio de los síntomas, hasta a 3 que se realizó a las 24 horas del inicio de los síntomas. Por lo que el tiempo de evolución de la enfermedad de los pacientes negativos no interfirió en la determinación. Todos estos pacientes fueron tratados sin oseltamivir, por carecer en ese momento del fármacos por lo que pertenecen al Grupo A.

\section{CONCLUSIONES}

En la población estudiada, en la Base Militar de Camp Arena en Herat presentó una tasa de ataque del 11,32\%, y la duración del bro- te fue de 19 días, datos similares en los brotes registrados en España en los meses de julio-septiembre de 2009.

En nuestro estudio la administración de oseltamivir redujo significativamente la duración de la fiebre en los pacientes con nueva gripe A H1N1 $(\mathrm{p}<0,001)$, respecto a los pacientes sin este tratamiento.

Los efectos secundarios del oseltamivir fueron frecuentes, y obligaron a la suspensión del tratamiento en el 11,29\% de los pacientes.

En nuestro estudio la sensibilidad y especificidad de la prueba de despistaje rápido con el kit BinaxNOW Influenza A\&B fueron menores que las referidas por el laboratorio.

\section{AGRADECIMIENTOS}

Los autores queremos agradecer a todo el personal del Role 2 en la Base Camp Arena en Herat (Afganistán), especialmente sanitarios, personal auxiliar, enfermeros y personal facultativo de los Roles 1 la inestimable ayuda que permitió seguir con nuestra labor asistencial a la baja de combate y afrontar el brote de nueva gripe A H1N1. Sin su ayuda este artículo hubiera sido imposible.

\section{BIBLIOGRAFÍA}

1. Casos humanos de la infección por nuevo virus de la gripe A/H1N1. Evolución de la situación mundial. Datos actualizados a 2 de julio de 2009. Ministerio de Sanidad y Política Social. En: www.msps.es.

2. Fe A, Ballester LE, Piñeyroa A, Toral JR, Mayo E, Gálvez EM. Primer brote de nueva gripe A(H1N1) en las Fuerzas Armadas españolas. Forma de presentación y medidas adoptadas. Sanid. Mil. 2009;65(3):172-177.

3. Información para los servicios de vigilancia epidemiológica de las CCAA. «Definición de casos humanos por nuevo virus de la gripe A/H1N1». Información actualizada de 07 julio 2009. Ministerio de Sanidad y Política Social. En: www. msps.es.

4. Casos humanos de gripe por virus pandémico (H1N1) 2009. Análisis descriptivo de las agrupaciones de casos en España. Ministerio de Sanidad y política Social. En: http://www.msc.es/profesionales/saludPublica/gripeA/docs/informeBrotes090925.pdf

5. Vaqué J. Epidemiología general de las enfermedades transmisibles. En: Piédrola. Medicina Preventiva y Salud Pública. $11^{\circ}$ Ed. Sierra A. Et al. Eds. Barcelona: Eselvier, 2008; 456.

6. Informe de actualización nacional. Situación de la gripe por Nuevo virus A(H1N1) en España. Ministerio de Sanidad y Política Social: Actualización de 6 de julio de 2009. En www.msps.es.

7. Burch J, Corbett M, Stock C, Nicholson K, Elliot AJ, Duffy S, et al. Prescription of anti-influenza drugs for healthy adults: a systematic review and meta-analysis. Lancet Infect Dis 2009;9:537-545.

8. Ficha técnica de Tamifluß. En: http://www.vademecum.es/medicamento-TAMIFLU reacciones 2653148

9. BinaxNOW A\&B Test kit. Inverness Medical. En: http://www.binaxnow.com/pdf/ IN416050\%20Rebranded\%20Influenza\%20A\&B\%20Rev\%204.pdf 